\title{
Problem-based learning spanning real and virtual words: a case study in Second Life
}

\author{
Judith Good $^{\mathrm{a} *}$, Katherine Howland ${ }^{\mathrm{b}}$ and Liz Thackray ${ }^{\mathrm{c}}$ \\ ${ }^{a} I D E A s$ Laboratory, Department of Informatics, University of Sussex, Brighton, UK; ${ }^{b}$ InQbate, \\ The CETL in Creativity, University of Sussex, Brighton, UK; ${ }^{c}$ Sussex Learning Network, Sussex \\ Innovation Centre, Brighton, UK
}

(Received 31 March 2008; final version received 8 September 2008)

\begin{abstract}
There is a growing use of immersive virtual environments for educational purposes. However, much of this activity is not yet documented in the public domain, or is descriptive rather than analytical. This paper presents a case study in which university students were tasked with building an interactive learning experience using Second Life as a platform. Both problem-based learning and constructionism acted as framing pedagogies for the task, with students working in teams to design and build a learning experience which could potentially meet the needs of a real client in innovative ways which might not be possible in real life. A process account of the experience is provided, which examines how the pedagogies and contexts (real and virtual) influence and enhance each other. The use of a virtual environment, combined with problem-based learning and constructionism, subtly changed the nature of the instructor-student relationship, allowed students to explore 'problematic problems' in a motivating and relevant manner, provided students with greater ownership over their work, and allowed problems to be set which were flexible, but at the same time allowed for ease of assessment.
\end{abstract}

Keywords: Second Life; problem-based learning; Immersive Virtual Worlds

\section{Introduction}

Immersive virtual worlds (IVWs) represent an important opportunity for teaching and learning. Although they can be used to replicate pedagogical events occurring in real life, they also offer a space to explore new methods of teaching and learning, or to investigate the teaching of issues which might be too difficult, dangerous or even impossible to contemplate in real life. Additionally, the social nature of IVWs represents a marked step up from simple discussion boards and forums, broadening communication channels to include social and cultural conventions operating in real life, and introducing new ones at the same time.

However, there is currently a paucity of research on IVWs for learning, particularly regarding their relationship to pedagogy. More needs to be known about the intersection between IVWs and pedagogy, and the ways in which IVWs might change the nature of a given learning experience. Similarly, more research is required to look at the ways in which teaching and learning can successfully negotiate and span the boundaries between real and virtual worlds.

\footnotetext{
*Corresponding author. Email: j.good@sussex.ac.uk
} 
In this paper, we report on a case study which investigated the use of Second Life (SL) by university students taking an interactive learning environments course to create innovative learning experiences for external clients (instructors in further education (FE) or higher education (HE)). In particular, we look at how a combination of pedagogical approaches, Problem-Based Learning (PBL) and constructionism, were used in conjunction with an immersive virtual world, SL, and at the ways in which the pedagogies and contexts (real and virtual) influenced and enhanced each other. We will argue that IVWs facilitate a series of novel interactions which can address some of the difficulties experienced when implementing PBL.

The rest of the paper is structured as follows: Section 2 provides a brief overview of the educational uses of SL, while Sections 3 and 4 describe the practical and theoretical setting for this work. Section 5 describes the unique contributions that SL can make to PBL, while Section 6 provides a brief conclusion.

\section{Educational uses of Second Life}

An increasing number of universities and colleges are represented in SL; approximately 36 UK universities have a formal presence in SL at the time of writing. Some are reproductions of real-world campuses (e.g. University of Sussex, Leeds Metropolitan University and Brunel University), or mix real-life and fantasy buildings such as Coventry University and the University of Hertfordshire. Many inworld university presences, such as the Virtual University of Edinburgh and the Heriot-Watt island, take advantage of the freedom offered by SL and create buildings and structures according to the needs of their inworld activities. University SL presences have received much press attention and are undoubtedly excellent tools for marketing and publicity. However, a number of universities have also begun to explore the potential of SL for teaching and learning. Much of this work is in the early stages, and there is a noticeable lack of publications which give a full evaluative account of teaching and learning projects in SL.

At Heriot-Watt University, students on a Multimedia Design course have undertaken SL projects which involved terraforming and building innovative interactive entities, as described on the Computers, Creativity and Learning Blog (Judy Robertson, 2008, http:// judyrobertson.typepad.com/judy_robertson/2008/01/index.html). The University of the West of England Research Observatory Blog describes how architecture students have been involved in the design of their inworld environment (http://hptftuwe.blogspot.com/). The Virtual University of Edinburgh provides inworld space for teaching courses including Masters degrees in E-learning and Design and Digital Media. The University of Warwick has a 'maths island' and Coventry University is also interested in supporting maths teaching and learning through SL, and is developing a virtual maths support centre (Savin-Baden and Chafer 2007). Coventry is also exploring SL's potential for supporting PBL (Savin-Baden 2007).

SL benefits from a vibrant educational community, evidenced, for example, by the very active Second Life Educator's mailing list (SLED). However, despite the affordances of this immersive virtual world, many SL educational experiences replicate traditional teaching scenarios. For example, there are many instances of lecture theatres in which instructors can, and do, give slide presentations, and many examples of teaching in SL are based on behaviourist models with a focus on knowledge transmission. Our investigation forms perhaps part of a new trend, as described by Larry Johnson, CEO of the New Media Consortium (NMC), currently the largest body of educators active in SL: "2007 was a year in which campuses made their entries into SL in great numbers, and as a result there is a 
considerable critical mass of educational institutions now existent in SL - more than 1200 educational islands were created in $2007, \ldots 2008$ also promises to see strong educational use of SL, but with a new focus. Projects in 2008 are much more likely to be about creating learning experiences than virtual campuses" (Levine 2008).

SL has the potential to allow instructors to design learning experiences which embody a number of different pedagogies, and to combine these pedagogies in potentially new ways. As an example, SL can support situated, active learning through the use of physical simulations, e.g. a simulation of a computer program, showing how data are processed and manipulated, or an engineering simulation which allows students to explore the workings of machinery. Simulations in education are by no means new. However, they have typically been single-user applications, where interaction takes place between a single learner and the simulation, rather than between multiple learners and the simulation.

In addition to the relative ease with which simulations can be built, SL offers a strong social component through the possibility for multiple avatars to engage in a given situation simultaneously allowing, for example, multiple learners to engage with one of the simulations above. However, SL's immersive nature allows learners not only to interact in situations in their role as learners, but to take on and experiment with new identities in the form of role-play. For example, learners might be able act out a particularly difficult social care encounter, or practice medical diagnosis skills. Here, the ability to change the appearance of one's avatar to fit the role being played, and to create a physical environment which mimics the real world, is likely to be a powerful contributor to the veracity of the simulation, and hence affect the actor's willingness to suspend disbelief.

This combination of physical simulations with role-play simulations can allow learners to simultaneously interact with physical entities and with each other. This, we believe, makes SL a potentially very powerful tool from an educational standpoint, and one we wished to explore.

In the section below, we describe the initial design for our investigation, covering a number of practical and contextual issues, before going on to describe the theoretical underpinnings.

\section{Method}

\subsection{Design}

The case study was designed in the context of an existing university course on interactive learning environments, where the aim was to investigate the extent to which Second Life could be used to create innovative learning experiences by putting the creation in the hands of the students themselves, who would design experiences for other students. The case study focused specifically on issues of process, considering the extent to which the use of Second Life in a primarily problem-based learning context changes the nature of the teaching and learning experience.

We first established a teaching team, consisting of the paper's authors. Within the team, one member was responsible for the overall running and facilitation of the course. Another acted as the SL expert, handling issues around access to SL, building, finances allocated to students, etc. The third was responsible for much of the technology facilitation and was involved in preparing and running sessions.

It was decided that students should work in teams to design a learning experience within SL. To ground the experience in a real-life context, project teams were paired with clients from Sussex Learning Network partner institutions to design learning experiences that corresponded to real curriculum needs within the vocational learning arena. The clients were 
asked to identify issues which were difficult, dangerous or impossible to teach in real life, to hold an initial meeting with the student team to outline their problem area, without offering a solution, and to provide additional input if required during the project. They were also invited to the project presentations, at the end of term, and their feedback was welcomed. A member of the teaching team was available to liaise with clients throughout the project.

By pairing external clients with student project teams, we aimed to provide clients with learning experiences which could potentially be used as is, or could form the basis for further development and/or reflection. We also wanted students to tackle a real-life problem, rather than one invented simply for the purpose of learning, and to have a tangible output which could be presented to their future employers.

The clients selected represented a wide range of curricular areas, including social work, nursing, police law and systems thinking, subjects which were well outside of the experience of the students on the course. In designing the project, we were conscious of the real-life requirement for IT professionals to understand and interpret domains and activities of which they have little or no direct experience in order to develop appropriate technical solutions, and felt that this experience offered an opportunity to develop skills which would translate well to real-life employment.

In terms of assessment, the SL learning experience comprised one element of a portfolio of work. The other components included the production of a machinima (a short film shot within SL) which showed the highlights of their learning experience, a group document describing the project overall, including the development process, and an individual document grounding the learning experience in the relevant literature, reflecting on the overall experience, providing a critique of their learning experience and engaging in a broader discussion of the value of IVWs for learning.

We hypothesised that engaging young people in the design of learning experiences in virtual environments might lead to innovative solutions. Rather than simply replicating reallife learning situations in SL, we hoped that the Web 2.0 generation would have a freedom to push boundaries in ways we might not consider. Similarly, by giving students the tools to design learning experiences within SL, we aimed to allow them to tap into their creative ideas for education, and bring those ideas to fruition in an environment unhampered by the laws and constraints of traditional physical educational spaces.

\subsection{Process}

A total of 41 students took part in the course. At the first course meeting, students were given a description of the research being carried out, and signed voluntary consent forms. Students then formed project teams (eight in total), were assigned an issue to investigate, and invited to an initial meeting with their client (either in person, or using teleconferencing facilities). Following this meeting, groups produced an initial specification for the design of their learning experience, and were given feedback from each member of the teaching team. The groups then began work on their learning experience, providing weekly updates to the teaching team in the form of notecards in SL, which allowed for feedback to be provided on a regular basis.

Members of the staff team were frequently present in SL throughout the course, and students were told that staff were available for discussion either in real life or SL. Impromptu visits were often arranged inworld to view and discuss progress. The final course session consisted of a presentation of each group's machinima, and was attended by many of the project mentors, in addition to a number of guests both internal and external to the university. 
We adopted a high-risk strategy by not only presenting students with real-life problems in areas they had little or no knowledge of, but also asking them to develop possible solutions - learning experiences - in an environment to which they had had little, if any, exposure. In order to mitigate the risks, the project was supported by eight sessions of two hours each, where students were introduced to a range of learning theories, initial orientation and building classes in SL and mentoring by a staff team experienced in interactive technologies, learning theory and SL. Sessions were highly interactive, and focused around topics which could potentially be of use in the students' project work, including the contributions of artificial intelligence to education, social software for learning, games and simulations. Students were assured that projects which tried to make full use of the affordances of SL and included a well-thought out reflection on the process, would receive high marks (even if not completely implemented).

Additionally, by taking a studio-based approach to teaching and learning (where students regularly discuss their progress with their peers in an open-ended way, and receive support and guidance from facilitators, both in a real space and in SL), we hoped to emulate the practices of interdisciplinary groups working on creative ideas for the design of learning environments.

\subsection{Data collection}

A number of different types of data were collected throughout the study. The primary source was the four pieces of assessed student work, described in Section 3.1. Given that both the group document and the individual document required significant reflection on the students' own learning processes, they provided important sources of data on the student perspective. Further sources of data were the weekly notecards completed by the groups in SL, email comments from students, group project workspaces (e.g. wikis, Google groups) and a standard online end of course assessment form used across the university, designed to measure the quality of the teaching and learning provision. We also conducted informal interviews with students, both in real life and inworld, and performed observations of project work, again both in real life and inworld, with a particular focus on how the project specification changed over time. Finally, the course team communicated on an almost daily basis to assess progress (both our own and that of the students), reflect on overall strategy and make decisions on any necessary interventions (e.g. how to deal with student stuckness). Although we also gathered feedback from the clients as they attended the final presentation and in discussions afterwards, this paper focuses on the learning process within the course itself, rather than on the value of the SL learning experiences which the students created.

\section{Theoretical underpinnings}

Underpinning the practical considerations in the design of the course were theoretical considerations on the nature of learning, and the best approaches for fostering learning.

The ILE course has traditionally been based on a constructivist and constructionist pedagogy. Constructionism (Harel and Papert 1991) maintains, in keeping with constructivist theories, that knowledge is constructed by the learner rather than transmitted from teacher to learner. Extending this central tenet, constructionism further argues that knowledge construction is particularly well supported when learners are engaged in building artefacts which are personally meaningful. It is also important that the entities created are public, as sharing a creation with others requires the learner to explain and talk about what they have constructed, including the process of construction. 
Thus, course sessions typically involve discussion and debate around readings, design exercises, and critiquing of software for learning, rather than lectures. Assessment is designed to allow for personal choice, is situated in a realistic context, and involves the creation of a tangible entity which can be viewed and commented on by others (e.g. in the form of peer reviews), rather than, say, essays.

However, in designing the SL learning experience, we recognised the applicability of a PBL approach, both in terms of the overall assessment, and in the content of many of the individual sessions.

PBL typically involves having students work in teams to explore a problem, with the tutor acting as a facilitator to this process. PBL has been used to describe a range of different learning activities, and has been confused with problem-solving learning (Savin-Baden 2000). At first sight, this project could appear to be the latter. However, the authors would argue that although the students were engaged in problem-solving activities, the absence of a clear or known solution - and indeed the probability of many possible solutions or approaches with no pre-determined expectations from the instructors - identifies this as PBL. Savin-Baden and Major (2004) differentiate PBL from problem-solving learning in the following way: in the latter, the instructor sets a problem which students solve in a stepwise logical manner, using resources provided by the instructor. The solution is largely pre-determined. On the other hand, PBL presents students with a problem, often scenario based, and students work in small self-directed teams to define, carry out and reflect upon the problem task, presenting their own solutions, which may not be those anticipated by the teacher. Ideally, there should be a crossing of disciplinary boundaries, although this is often difficult to achieve in practice, particularly when PBL must be implemented 'on a shoestring', i.e. in a single course, rather than across a curriculum (Savin-Baden and Major 2004). Originally developed in the medical field, PBL is frequently used in disciplines where practitioners are faced with problems on a daily basis and learning to work in a team is a necessary part of their training.

PBL is now a recognised approach in a number of subject domains, and the various facets of PBL have been explored in depth, including its defining characteristics (Boud and Feletti 1997), categorisation of problem types (Schmidt and Moust 2000) and facilitator roles (Wilkerson and Hundert 1997; Savin-Baden 2003). It is a rich discipline taking a variety of different forms. Drawing on the work of Boud (1985) and Barrows (1986), SavinBaden (2000) has offered taxonomies and descriptions of a number of different models of PBL, and argues that the form of PBL being used should be made explicit both within the curriculum and to students. The model we adopted was a variation of the problem-based model in which students meet with a client in some form of simulated format that permits free enquiry (Barrows 1986) combined with PBL for transdisciplinary learning.

In this model of problem-based learning, students are encouraged to adopt a critical position towards knowledges, themselves and their peers, and to use the problem-based learning group as a place in which to examine and test out personal and pedagogical frameworks. (SavinBaden 2000, 132)

The ILE course assessment was a good match in terms of the characteristic features of PBL as defined by Boud and Feletti (1997); students began with an open-ended problem in the form of a difficult issue to teach in real life. They formed into teams to tackle the problem, and were invited to use a range of resources on learning approaches together with the affordances of SL to develop possible interactive learning experiences in SL. The group explored the issue both in and out of class time, with access to the teaching team on an asneeded basis. Once an initial solution was sketched out, students needed to determine the 
skills and information to be acquired (e.g. subject-specific information from their client, building and scripting skills in SL) and define team member responsibilities. Through an iterative process of development, they then explored ways of addressing the problem scenario. Lastly, they self-evaluated their outputs, both individually and as a group.

Interestingly, our teams had a degree of interdisciplinarity. Although based in a school of science and technology, the Master's programmes from which students were drawn (Human-Centred Computing Systems, Intelligent Systems and Multimedia and Virtual Environments) are conversion courses designed for students from a wide variety of backgrounds. Although more firmly grounded in the computer science field, undergraduate students were also enrolled on different degree programmes, from straight computer science, to degrees such as Music Informatics, Internet Computing, and combinations of subjects such as Artificial Intelligence and German.

Finally, the constructionist component of the exercise, which required project teams to design a learning experience in SL, produced a tangible output to the PBL process, hence facilitating assessment, and allowing us to evaluate the process, the product, and students' own assessment of their work.

\section{Unique contribution of Second Life to PBL}

Although lauded for providing authentic learning opportunities, PBL also presents challenges for educators. It requires that instructors consider a number of issues when deciding to adopt it, including methods of assessment (Duch and Groh 2001). A further concern is ensuring that the problems chosen do not leave students with a narrowed field of experience in terms of the curriculum (Ryan 1997). Instructors also need to consider how they can move from a traditional lecturer role to one of facilitator, and how students can adapt to their new roles without experiencing concomitant anxiety as a result of the open-endedness of the PBL process (Savin-Baden and Major 2004). Finally, there is a danger that facilitation can be reduced to "a skills-based task that focuses purely on process and ignores the quality of what students actually produce and feed back to the group" (Savin-Baden 2000, 132).

A virtual world offers the opportunity to adopt new approaches to PBL. Savin-Baden (2007) has argued that there is a need to reinvent PBL as a much more troublesome learning space than is currently the case, and has drawn attention to the possible connection with threshold concepts and troublesome learning as discussed by Meyer and Land (2006). We suggest that the use of an immersive virtual world such as SL in combination with PBL allows one to address key issues in meaningful ways, described below.

\subsection{Supporting role of tutors and students}

SL allows the role of the tutor to be 'blurred' in a number of ways. The tutor is unlikely to be an expert on all aspects of SL, in addition to the subject matter in question, and must therefore suggest appropriate ways for the students to gain the knowledge and skills they need. This, in turn, is supported by the extensive online community which exists within SL: tutorials, resources, information and support are available from a wide variety of sources, and students are likely to consult others inworld for help and guidance. Embedding the learning in the wider community in this way provides a concrete model of the collaborative nature of learning and problem solving.

SL facilitates the provision of ongoing feedback to students. Students are aware of when their tutors are inworld, and we found our students very keen to teleport us to their location in SL in order to demonstrate their work and obtain feedback. 
There are also more subtle changes in the relationship between tutors and students which arise from modes of communication and self-presentation inworld. For students, chatting with the instructor's avatar was a very different experience to speaking with one's instructor in real life, and a number of informal and wide-ranging conversations ensued between students and members of the teaching team which are unlikely to have occurred in real life. Again, we feel that this reinforced the role of the instructor as a source of guidance and, in some cases, a peer rather than an authority.

\subsection{Motivation and relevance}

Creating an entity in a virtual world such as SL, which is often commented on in the press, ensures that the project has high relevance to students. It is a new and exciting area in which to be working, and most students are likely to see the ability to create artefacts in an online virtual world as a powerful skill. One student remarked on the course evaluation questionnaire: "It has opened new doors to an entirely different field of computing, which is very interesting, and the course has made me realize that there is so much potential out there to do anything you can think of!" SL supported our constructionist approach well, ensuring that students develop knowledge and skills through the creation of a public entity which has meaning and significance for them and for others. Another student, commenting on the final presentation in an email to the instructors, remarked that, "It was good to see so many prominent people in the department, as well as students and staff not on the course taking such an interest in our work".

\subsection{Problematic problems}

The cutting-edge nature of the environment ensures that there are no simple answers to problems set. Whilst most real-world problems have been attempted in some form, SL is still a relatively new environment. In tackling the problems devised by our clients, students were obliged to develop their own solutions, as there were no examples of existing solutions to which they could refer in SL. Although they could make use of previously solved low granularity problems, such as creating a chat-bot, they needed to build new components and combine existing ones in novel ways.

One of the more difficult aspects of the project for us as instructors was knowing what the students were actually doing. Initially there was a deathly silence when we wondered if anything was happening at all. This was accompanied by the flight into activity of one group which began to build an enormous edifice containing classrooms. Our presupposition that students would have less baggage than their instructors was called into question; it appeared that though the students might have less baggage, they also had less experience of education other than that delivered in formal settings, and they escaped to the familiar surroundings of building lecture theatres. This reflects Savin-Baden's (2007) observation of the stuckness that can occur in the learning process and her identification of a number of possible responses, including an avoidance of the task and a retreat to the familiar.

However, as the course progressed and students became more confident in the SL environment, a number of the groups moved away from the large formal builds into doing things only possible in a virtual environment, such as creating a magic forest where works of art hung from the branches of trees, or building a large retail outlet and superimposing a layer - only visible by flying above the building - of systems diagrams relating to the operation of the store. The students had moved beyond their stuckness to a position where they had 
not only mastered a new environment, but had used it to create new and inventive learning possibilities.

\subsection{Flexibility}

SL provides good support for setting open-ended problems for students. In the real world, limiting factors can mean that attempts to set open-ended problems are foiled by practicalities such as the availability of resources, or constraints on scale. In SL, although activities are not constraint-free, there is a much greater range of possible solutions and directions in which students can choose to take problems. The flexibility of SL also makes it possible for a problem to be simplified in the early stages of a PBL project process by removing factors which would need to be addressed in real life, for example, by providing ready-made scripts or objects for users to work with to allow them to focus on a specific area of a problem.

\subsection{Ownership}

The freedom from real-world limiting factors allows students to take greater ownership of their project, as there is less need for them to check or consult with someone in a position of authority. Although there are risks in SL, it offers a safe environment for experimentation. This can enhance the sense of responsibility groups feel for their work. The strength of the online community surrounding SL can further support student independence. Online forums, weblogs, wikis and other sites are available which can provide answers to almost any question a student may have about how to achieve something inworld. This empowers the students further as they can quickly identify areas in which their knowledge is lacking and set about developing the skills required by doing their own research.

\subsection{Ease of assessment}

Work carried out in SL is easily viewed and appreciated. Entities created can be explored by tutors at various stages of the PBL process. Additionally, creating machinima provided an ideal way for the student groups to reflect on their problem solutions and a convenient way for tutors to gain an insight into the artefacts created. Nonetheless, it is worth noting that if students are creating entities in SL, especially when they are large and complex, there may well be issues around submitting them for assessment (for example, land may need to be rented on which to house the entities, or if they are submitted by placing them in the instructor's inventory, there may be issues around how to rebuild them, etc.).

\section{Conclusion}

As described above, the process of combining PBL and constructionism with problems which spanned the real world and a virtual world brought with it a number of advantages. Overall, student feedback was very positive, which is heartening, considering the potential for anxiety associated with tackling open-ended, real-world problems in an unfamiliar environment.

At the same time, there is potential for improvement, although we would argue that many of the problems we encountered were less to do with the combination of PBL and SL, than with our own implementation of PBL. For example, although we felt that we had addressed the issue of group versus individual responsibility via the individual reflective 
component, in retrospect we realised that we had not implemented individual accountability in the design of the SL learning experience, with the result that some team members were much less active and engaged than they might have been. Similarly, we did not provide explicit support for the acquisition of team skills. We plan to address both of these issues in the next academic year.

Nonetheless, the combination of PBL with SL provided a number of distinct advantages, offering an ideal venue in which to exercise authentic problem-based learning, reinforcing the facilitative role of the instructors, whilst offering motivation and relevance for the students. Overall, immersive virtual worlds offer an exciting opportunity to both consolidate existing pedagogical practices and extend them in new ways.

\section{Acknowledgements}

Thanks to Diane Brewster for initial discussions on problem-based learning, and to our students, for their creativity and enthusiasm. We are also very grateful to InQbate, the Centre of Excellence in Teaching and Learning (CETL) in Creativity at the University of Sussex, who funded this work via the Creativity Development Fund.

\section{References}

Barrows, H.S. 1986. A taxonomy of problem-based learning methods. Medical Education 20: 481-6.

Boud, D. 1985. Problem-based learning in education for the professions. Sydney: Higher Education Research and Development Society of Australasia.

Boud, D., and G.I. Feletti. 1997. Changing problem-based learning. Introduction to the Second Edition. In The challenge of problem-based learning, 2nd ed., ed. D. Boud, and G.I. Feletti, 1-14. London: Kogan Page.

Duch, B.J., and S.E. Groh. 2001. Assessment strategies in a problem-based learning course. In The power of problem-based learning, ed. B.J. Duch, S.E. Groh, and D.E. Allen, Sterling, 95-107. VA: Stylus Publishing.

Harel, I., and S. Papert. 1991. Constructionism. Norwood, NJ: Ablex.

Levine, A. 2008. NMC virtual worlds announces plans for 2008. NMC Campus Observer. http:// sl.nmc.org/2008/01/16/nmc-virtual-worlds-2008/.

Meyer, J.H.F., and R. Land. 2006. Threshold concepts and troublesome knowledge: Issues of liminality. In Overcoming barriers to student understanding: Threshold concepts and troublesome knowledge, ed. J.H.F. Meyer and R. Land, 19-32. Abingdon: RoutledgeFalmer.

Ryan, G. 1997. Ensuring that students develop an adequate, and well-structured, knowledge base. In The challenge of problem-based learning, 2nd ed., ed. D. Boud, and G.I. Feletti, 125-36. London: Kogan Page.

Savin-Baden, M. 2000. Problem-based learning in higher education: Untold stories. Buckingham, UK: SRHE/Open University Press.

- 2003. Disciplinary differences or modes of curriculum practice? Who promised to deliver what in problem-based learning? Biochemistry and Molecular Biology Education 31: 338-43.

- 2007. Second Life PBL: Liminality, liquidity and lurking. Keynote speech at the Reinventing Problem-based Learning Conference, March 7-9, at the Republic Polytechnic, Singapore. http://www.elu.sgul.ac.uk/preview/documents.htm.

Savin-Baden, M., and J. Chafer. 2007. Learning on the MUVE: Islands in the sun? Innovate Magazine 2, Autumn, Coventry University. http://www.elu.sgul.ac.uk/preview/documents/publications/ Learning_on_the_MUVE_final.pdf.

Savin-Baden, M., and C.H. Major. 2004. Foundations of problem-based learning. Maidenhead, UK: Open University Press.

Schmidt, H.G., and J.H.C. Moust. 2000. Towards a taxonomy of problems used in problem-based learning curricula. Journal on Excellence in College Teaching 11, no. 2/3: 57-72.

Wilkerson, L., and E.M. Hundert. 1997. Becoming a problem-based tutor: Increasing self-awareness through faculty development. In The challenge of problem-based learning, 2nd ed., ed. D. Boud, and G.I. Feletti, 160-72. London: Kogan Page. 